\title{
The metalinguistic use of vague predicates in conditionals *
}

\author{
Stefan Hinterwimmer \\ University of Osnabrück
}

\begin{abstract}
This paper deals with an at first sight surprising reading that indicative conditionals whose antecedents contain vague predicates receive under certain conditions. I argue that the existence of this reading can be explained if indicative conditionals are allowed to receive a special kind of metalinguistic interpretation. According to this reading, the worlds quantified over do not (possibly) differ from the world of evaluation with respect to some extralinguistic state of affairs, but only with respect to the standards according to which the vague predicates in the antecedents are interpreted. I show that the availability of the metalinguistic reading can be accounted for if both the epistemic modal bases and the selection function relative to which the worlds quantified over are determined are allowed to operate in a more flexible way than is standardly assumed.
\end{abstract}

Keywords: vagueness, conditionals, metalinguistic readings, clefts

\section{Introduction: the puzzle}

Consider the conditionals in (1). They all have prominent readings that can be paraphrased as in (2):

(1) a. If I hate anything, it's bad acting.

b. If anyone was drunk at last night's party, it was Mary.

c. If any book impressed me, it was Ulysses.

(2) a. What I hate most is bad acting.

b. The drunkest person at last night's party was Mary.

c. The book that impressed me most was Ulysses.

As the paraphrases suggest, the sentences are compatible with, i.e. can be true in a situation where it is clear that there is more than one thing that the speaker hates, more than one person that was drunk at last night's party, etc. The conditional in (1b), for example, could naturally be uttered in a situation where two people, say Jack and Jill, are talking about a party they both attended on the prior evening, and

* I would like to thank Cornelia Ebert, Andreas Haida, Hans Kamp, Angelika Kratzer, Manfred Krifka and Sophie Repp as well as the audience at SALT 20 for helpful discussion and comments. 
The metalinguistic use of vague predicates in conditionals

where Jill just said that their common friends Bob and Mary were both drunk at the end of the party. The crucial point is that by uttering (1b) in response to Jill's claim, Jack does not necessarily express his disagreement, i.e. he may well agree that Bob and Mary were drunk and just wants to say that Mary was the drunkest of them all. Similar scenarios can easily be construed for (1a) and (1c). The examples in (1) all have a cleft-like structure. This is evidenced by the fact that the pronoun preceding the copula in the consequent has to be a neuter pronoun, no matter what the gender of the individual referred to by the post-copular DP is. This holds even in cases where the any-phrase in the antecedent already indicates that the individual referred to by the post-copular DP is male or female:

a. If any of Bob's girlfriends impressed me, it was Claire.

b. *If any of Bob's girlfriends impressed me, she was Claire ${ }^{1}$.

It is well-known that clefts are interpreted exhaustively (see Hedberg 2000 and the references cited therein), as shown by the contrast between (4a) and (4b):

(4) a. It was Paul who solved the problem. \# And Mary did, too.

b. Paul solved the problem. And Mary did, too.

But if we combine this fact about the interpretation of clefts with standard assumptions about the meaning of conditionals, it is completely unexpected that the sentences in (1) have the readings paraphrased in (2). Rather, we would expect them to only have readings that can be characterized along the following lines:

(A) The speaker at least implicates that she is not sure whether an entity exists in the world of evaluation that satisfies the antecedent predicate, i.e. that is hated by her, was drunk at last night's party, etc.

(B) In all worlds that are epistemically accessible from the world of evaluation (i.e. where everything that is known in the world of evaluation is true) and where an entity that satisfies the antecedent predicate exists, the unique entity that satisfies the antecedent predicate is identical to the individual referred to by the post-copular DP.

Note that I am not claiming that the sentences in (1) do not have readings that can be characterized along these lines (at least (1b) certainly does). The crucial point for me is just that they also have prominent readings that can be paraphrased as in (2). In this they contrast with the sentences in (5), which can only be interpreted along

1 The sentence is grammatical under a completely irrelevant and absurd reading, which in my view is almost impossible to get, and which can roughly be paraphrased as follows: In all accessible worlds where one of Bob's girlfriends impressed me, some contextually salient female individual was identical to Claire. 
the lines sketched in (A) and (B), i.e. (5a) is incompatible with a situation where the speaker considers it possible that there is an individual apart from Peter that can solve the problem under discussion, etc.

a. If anyone solved this problem, it was Peter.

b. If Peter bought anything at the store, it was pizza.

Intuitively, this difference is due to the following fact: The antecedent predicates in (1) are gradable, i.e. one can hate something to a higher or lesser degree, be drunk to a higher or lesser degree, etc. The ones in (5), in contrast, are not: A problem is either solved or not solved by someone, and something is either bought by an individual or not bought. Now, with the exception of so-called absolute gradable adjectives like full, open, wet or dry (see Kennedy 2007 for discussion) ${ }^{2}$, gradability of a predicate results in vagueness concerning the standard with respect to which the respective predicate is interpreted if it does not occur in combination with an explicit measure phrase (or, in the case of gradable adjectives, with a comparative or superlative morpheme). It is thus plausible to assume that the standard of interpretation is left open in such cases and can be fixed by the context (cf. von Stechow 1984; Kennedy 1999, 2007; Barker 2002 on gradable adjectives). Consequently, the intensity of the negative stance a person must have towards an entity in order for the pair consisting of the person and the entity to be in the denotation of hate, for example, can vary from context to context. As we will see below, it is this fact that allows us to give a principled explanation of why the conditionals in (1) receive readings that are not available for the ones in (5).

So while vagueness of the respective antecedent predicate is crucial for the availability of the readings that are the main focus of this paper, another factor that at first glance might seem to play a role as well can immediately be dismissed: the presence of the Negative Polarity Item (henceforth: NPI) any in the antecedent of the conditional. It is well-known that NPIs are licensed in the antecedents of conditionals

2 As Kennedy (2007) shows in detail, what distinguishes those adjectives from other gradable adjectives is the fact that in order for an entity to fall under their denotation, it either suffices that it possesses the relevant property to a minimal degree (i.e. a table is wet as soon as there are a few drops of water on its surface), or it is required to possess the property to a maximal degree (i.e. a glass is only full if it is completely filled). Kennedy shows that this special behavior of absolute gradable adjectives (i.e. the absence of a context-sensitive interpretation in spite of their gradability) is due to the interplay of two factors:

(i) the special nature of the scales with which they are associated: in contrast to the scales associated with other gradable predicates, those scales have natural upper or lower bounds. an interpretive principle which favors conventional meaning over context-dependent meaning. 
The metalinguistic use of vague predicates in conditionals

quite generally, despite the fact that conditional antecedents fail classical tests for downward-entailingness (but see von Fintel 1999 for a modified version of the notion of downward-entailingness that works for conditionals). This is also evidenced by the examples in (5), which do not have readings of the kind under consideration, but which contain any-DPs as well. Still, it is conceivable that while hardly being a sufficient condition, the presence of any is a necessary condition nonetheless. This cannot be the case, however, since the following variants of the examples in (1) can also be interpreted as paraphrased in (2) (though some of the native speakers I consulted judged them as slightly dispreferred):
a. If I hate something, it's bad acting.
b. If someone was drunk at last night's party, it was Mary.
c. If some book impressed me, it was Ulysses.

In addition to that, the German equivalents of the examples in (1), which contain 'ordinary' indefinite pronouns/indefinite DPs instead of NPIs ${ }^{3}$, get the relevant readings as easily as their English counterparts:
a. Wenn ich etwas hasse, ist es schlechte Schauspielerei.
If I something hate it is bad acting.
b. Wenn jemand auf der Party gestern abend betrunken war, war es If someone at the party yesterday evening drunk was was it Maria.
Maria
c. Wenn mich ein Buch beeindruckt hat, war es Ulysses. If me a book impressed has was it Ulysses

This shows clearly that the distribution of NPIs in the antecedents of conditionals, while being an interesting topic in its own right, is independent of the question of how the readings arise that that are our main concern in this paper.

The paper is structured as follows: Section 2 discusses some additional data that give us a clearer picture with respect to the question of which antecedent predicates license the 'unexpected readings' under consideration. Section 3 spells out in a little more detail what the 'expected readings' of the relevant examples are and how they come about given standard assumptions about vague predicates, conditionals and clefts. Section 4.1 briefly summarizes the main features of Barker's (2002) analysis of vague predicates, on which my own account is based, setting the stage for a presentation of my analysis in section 4.2. Section 5 is the conclusion.

3 There is no equivalent of NPI-any in German. 
Stefan Hinterwimmer

\section{More data}

In section 1 we have seen that the presence of gradable and thus vague predicates (but see footnote 2 for qualification) is required in the antecedents of conditionals in order for the 'unexpected readings' under discussion to arise. Since the predicates in (1a) and (1c) are verbs, not adjectives, they cannot be combined with comparative and superlative morphemes directly. Still, their gradability is evidenced by the paraphrases in (2a) and (2c): The VP the respective verb heads is modified by the adverb most, which is the superlative version of the adverb more, and its presence in the VP intuitively has the same effect as the modification of the adjective drunk by the superlative morpheme in (2b). (I will discuss the semantics of gradable predicates in more detail in sections 3 and 4.)

Now consider the sentence in (8a), which likewise receives a prominent reading of the kind under consideration (paraphrased in $(8 b))^{4}$ : As the contrast in $(8 b)$ shows, however, the verb understand in the antecedent predicate in (8a) cannot felicitously be modified by most. Rather, the adverb best has to be chosen, which is the superlative version of the adverb well.

a. If anybody/somebody understands the work of Michael Haneke, it's Isabelle Huppert.

b. The one who understands the work of Michael Haneke best/?? most is Isabelle Huppert.

This contrast between the examples in (1), on the one hand, and the example in (8a), on the other, is presumably due to the fact that gradable predicates are associated with different dimensions that are mapped onto degrees (see section 4 below for more details), and on which comparative and superlative morphemes or adverbs performing parallel functions operate: In the case of the verbs hate and impress and the adjective (be) drunk, it's the pure intensity of a certain emotional or physical state that a person is in. In the case of the verb understand, it's much harder to pin down the dimension to be manipulated, since even the choice of dimension seems to depend on contextual factors: Intuitively, what seems to be at stake (in cases like the one under consideration, where the object is a piece of art) are properties like being able to integrate various parts into a coherent structure, having a clue as to what the motivation of the artist is, etc. It might be this additional complexity and subjectivity

4 Note that in contrast to the sentences in (1), the paraphrased reading is not clearly the preferred one in this case. Rather, interpreting the sentence in this way is just an available option, with the "expected reading' being another one, according to which the speaker is (a) not sure whether anyone exists at all who understands the work of Michael Haneke, and (b) that in case such a person exists, it is identical to Isabel Huppert. The choice between these two readings presumably depends on contextual factors as well as on the hearer's own stance towards the work of Michael Haneke. 
The metalinguistic use of vague predicates in conditionals

that is responsible for the fact that VPs headed by understand have to be modified by the adverb best instead of most. Be that as it may, the important point for our purposes is that the example in (8a) provides additional evidence for our hypothesis that the gradability of the antecedent predicate is crucial for licensing the readings under consideration.

But now consider the conditionals in (9), whose antecedents do not contain VPs headed by verbs that qualify as gradable:

a. If I read anything/something, it was Finnegan's Wake.

b. If anybody/somebody is pregnant in this room, it's Mary.

Still, (9a) can be uttered felicitously and truthfully by a speaker who is known (and knows himself) to have read lots of books, and (9b) by a speaker who is known (and knows himself) to be in a room with various pregnant woman. In other words, they do not necessarily receive the expected readings either. But how can their 'unexpected readings' be characterized? Intuitive paraphrases are given in (10):

(10) a. The book I studied/thought about most intensely is Finnegan's Wake.

b. The woman who shows the strongest/most obvious signs of pregnancy in this room is Mary.

The paraphrases in (10) are structurally parallel to the paraphrases of our examples containing gradable predicates. Intuitively, the difference is that in the examples above gradability is part of the respective predicate's lexical semantics, while in the case of the sentences in (9) the basic denotation has to be modified: The predicates come with (relatively) clear criteria specifying whether an entity falls under their denotation or not, i.e. a woman satisfies the property of being pregnant as soon as she has a fertilized egg cell in her uterus, and a person satisfies the property of having read a book as soon as s/he has finished the last page. On the other hand, there are associated predicates that individuals can be assumed to satisfy as soon as they satisfy the respective original predicate, and at least some of these properties are gradable: The belly of a pregnant woman grows bigger over the course of her pregnancy, for example; reading a book is associated with thinking about its content, etc.

Let us therefore assume that it is these associated gradable properties which enable the sentences in (9a) and (9b) to receive their 'unexpected readings'. I.e. the original denotations of the respective antecedent predicates are shifted in such a way that these properties are turned into criteria an individual necessarily has to satisfy in order to fall under the denotation of the predicate. As soon as this has happened, the same mechanism (which will be discussed in detail in section 4) can apply that applies in the cases where the antecedent predicates are gradable to begin with. 
Now, of course, different properties can be selected in different contexts: While the most obvious choice in the case of (9b), for example, is the property of having a belly that grows bigger over the course of pregnancy, other choices are conceivable as well. In a context where the assumption that pregnant woman tend to unpredictable and undermotivated emotional outbursts is part of the interlocutors' shared beliefs, for example, and where Mary has just behaved in such a way, (9b) may well be understood as follows: Mary is the one among the contextually salient pregnant women that shows the irrational behavior which is assumed to be associated with pregnancy in its most extreme form.

Let us finally turn to the sentence in (11), which can felicitously be uttered by a speaker who is known (and knows himself) to have talked to various people at the relevant party. This shows that it receives a reading of the kind we are interested in.

If I talked to anybody/somebody at the party yesterday, it's Paul.

The antecedent predicate is vague in the following sense: It is not clear how many utterances one really needs to have exchanged with a person $x$ in order for it to be true that one has talked to $x$. What seems to be clear is that mutual greetings would not be enough, but apart from that one does not have the feeling that it is possible to define a lower threshold either in terms of the time spent together or the number of utterances exchanged. It is thus not surprising that a natural paraphrase of (one of the possible readings of) (11) involves manipulating the temporal dimension:

(12) The person I talked to longest at the party yesterday is Paul.

Interestingly, however, I have the clear intuition (which is shared by my informants) that the sentence can even be true in a situation where the speaker has talked to other people longer than to Paul, but where the other conversations were rather superficial, and the one with Paul was the only one where really substantial issues were discussed. Sticking to the schema adopted for the other examples under discussion, the following paraphrase suggests itself for this way of interpreting the sentence:

(13) The person I talked to most intensely at the party yesterday is Paul.

The availability of the reading paraphrased in (13) in addition to the one paraphrased in (12) can be interpreted in two ways: According to the first one, it shows that another dimension is involved in the original denotation of the verb talk to, which is also vague and accordingly can be interpreted with respect to different standards in different contexts. According to the second one, it shows that even a predicate that is vague along a particular dimension qua lexical meaning can be shifted in a manner that is parallel to the way the (initially) non-vague predicates in (9) can be shifted: 
The metalinguistic use of vague predicates in conditionals

Namely by turning an associated dimension into a part of the core lexical meaning. At present, I do not see a way to decide between these two options, and simply note that they are both compatible with the view adopted in this paper: Namely that gradability (either qua lexical meaning or as a result of a shifting operation) of the antecedent predicate is required in order for conditionals to receive the "unexpected readings" under consideration. Before turning to my account of how these readings actually arise, let us first get a clearer understanding of the way in which they deviate from what we would expect to be the only available interpretations.

\section{The 'expected' readings}

According to the view shared by most (formal) semanticists, indicative conditionals (very roughly) express universal quantification over those worlds where the respective antecedent is true that are epistemically accessible from the world of evaluation (Kratzer 1986; von Fintel 1997, 1999; Nolan 2003; cf. Stalnaker 1975 for a slightly different, though related view). Since the question of whether this is due to the meaning of if (as argued for by Gillies (2010)), or to the presence of a covert epistemic operator with universal force (with if simply signaling that the $\mathrm{CP}$ it heads is to be interpreted in the restrictor of an operator, as argued for by Kratzer (1986)), is irrelevant for our present concerns, let us adopt the second option for concreteness

Kratzer (1981) assumes that modals in general do not only operate on modal bases, i.e. on functions from possible worlds to sets of propositions, but that the set of possible worlds where all the propositions in the modal base are true is further restricted by an ordering source, where an ordering source is a set of propositions that characterizes the world of evaluation in a certain respect. A modal thus quantifies over those worlds where all the propositions in the modal base are true that conform as much as possible to the description provided by the ordering source, i.e. that make as many of the propositions in the ordering source true as possible.

Now, since indicative conditionals contain a (covert) epistemic modal with universal force by assumption, their truth conditions can be characterized as follows. Assuming that a stereotypical ordering source is employed by default, i.e. an ordering source containing assumptions about the stereotypical course of events in the world of evaluation: An indicative conditional with antecedent $p$ and consequent $q$ is true in a world $w$ iff in all those among the worlds where $p$ is true and that are compatible with what is known in $w$ that conform as much as possible to stereotypical assumptions about the course of events in $w, q$ is true as well. This is given schematically in (14c), with (14a) providing the formal definition of a strict partial order $<_{P}$ over a set of propositions $P$, and (14b) the definition of the selection function $\max _{P}$ that selects the set of $<_{P}$-best worlds from any set $X$ of worlds (see von Fintel \& Iatridou 2005: 4f.). 
a. $\forall w^{\prime}, w^{\prime \prime}: w^{\prime}<_{P} w^{\prime \prime}$ iff $\forall p \in P\left(w^{\prime \prime} \in p \rightarrow w^{\prime} \in p\right) \wedge \exists p \in P\left(w^{\prime} \in p \wedge\right.$ $\left.w^{\prime \prime} \notin p\right)$

'A world $w^{\prime}$ is better than a world $w^{\prime \prime}$ with respect to a set of propositions $P$ iff all propositions in $P$ that are true in $w^{\prime \prime}$ are true in $w^{\prime}$ as well, and there is at least one proposition in $P$ that is true in $w^{\prime \prime}$, but not in $w^{\prime}$.'

b. $\forall X \subseteq W: \max _{P}(X)=\left\{w \in X: \neg \exists w^{\prime} \in X: w^{\prime}<_{P} w\right\}$

'The selection function $\max _{P}(X)$ selects the worlds from $X$ that are best with respect to $P$, i.e. that make as many of the proposition in $P$ true as possible.'

c. $\quad \llbracket$ MUST if $p, q \rrbracket^{f, g}=\lambda w . \forall w^{\prime}\left[w^{\prime} \in \max _{g(w)}(\cap(f(w)) \cap \llbracket p \rrbracket) \rightarrow w^{\prime} \in\right.$ $\llbracket q \rrbracket)]$, where MUST is the covert counterpart of overt epistemic must, $f$ is the modal base, and $g$ is the ordering source.

Before we can take a closer look at what this analysis gives us when it is applied to the examples under consideration, we first need to consider vague predicates as well as the contribution of the neuter pronoun it in the consequent of the conditional in a little more detail. As already said above, gradable predicates are standardly assumed to either denote relations between individuals and degrees to which those individuals satisfy the respective predicates (von Stechow 1984; Kennedy 1999), or as functions from individuals to measurements, i.e. the degrees to which they possess the respective property (Kennedy 2007). Irrespective of which option is chosen, in order to combine with their subject arguments, they need to be turned into functions from individuals to truth values. Let us adopt the first option for the moment (but see section 4 below), and follow von Stechow's (1984) analysis of gradable adjectives. Simplifying somewhat, von Stechow assumes that gradable adjectives like tall take an additional degree argument, which can be saturated by measure phrases like three inches or via the combination with comparative or superlative morphology.

Now, the crucial question for our purposes is of course what happens in those cases where neither measure phrases nor comparative or superlative morphology is present. According to von Stechow, the adjective in such cases is combined with a covert morpheme pos, which introduces a standard of comparison in the form of a free variable $d_{s}$ ranging over degrees whose value is fixed by the context. Let us modify this analysis in such a way that it applies to transitive verbs, i.e. let us assume that there is a related covert morpheme pos $_{t r}$, which can be combined with transitive verbs such as hate:

$$
\text { a. } \quad \llbracket \operatorname{pos}_{t r} \rrbracket=\lambda f_{<d,<e,<e, s t>>>} . \lambda y \cdot \lambda x . \lambda w . \exists d\left[f(d)(y)(x)(w) \wedge d \geq d_{s}\right]
$$


The metalinguistic use of vague predicates in conditionals

$$
\begin{array}{ll}
\text { b. } & \llbracket \text { hate } \rrbracket=\lambda d \cdot \lambda y \cdot \lambda x \cdot \lambda w .[\text { hate }(d)(y)(x)(w)] \\
\text { c. } & \llbracket \text { pos }_{t r}-\text { hate } \rrbracket=\lambda y \cdot \lambda x \cdot \lambda w . \exists d\left[\text { hate }(d)(y)(x)(w) \wedge d \geq d_{s}\right]
\end{array}
$$

Let us now turn to the contribution of the neuter pronoun it. As already said in the introduction, the obligatoriness of a neuter pronoun in the consequent of the conditional indicates a cleft-like structure, and clefts are known to trigger exhaustiveness effects. According to Hedberg (2000), this is due to the semantic contribution of $i t$ : She assumes that $i t$ has the same meaning as the definite article, i.e. it is a function from sets to individuals that is only defined for singletons, and returns the unique member of the respective set. This, in combination with a syntactic analysis which treats the cleft clause as forming a discontinuous constituent with the cleft subject pronoun, accounts for the truth-conditional equivalence of a cleft sentence such as (16a) with a sentence such as (16b): Applying the meaning of it to the predicate denoted by the CP who stole the watch gives us the same semantic object as the one we get by applying the meaning of the to the predicate denoted by the NP person who stole the watch.

a. It was Peter who stole the watch.

b. Peter is the person who stole the watch.

Let us follow Hedberg in assuming that the neuter pronoun in the conditionals under consideration has the same denotation as the definite article. Let us furthermore assume that it in these cases does not have a syntactic complement to combine with, but rather comes with a free variable ranging over predicates which is resolved to the most salient predicate in the context. Since the most salient predicate in our examples is the one introduced in the antecedent of the respective conditional, the free variable is resolved to it, and we get an interpretation according to which the neuter pronoun denotes the unique individual satisfying the antecedent predicate relative to each of the worlds quantified over.

Combining these assumptions with the ones about vague predicates and with the analysis of indicative conditionals sketched above, we get (17b) as the denotation of (1a), which is repeated here as (17a):

a. If I hate anything, it's bad acting.

b. $\quad \lambda w . \forall w^{\prime}\left[w^{\prime} \in \max _{g(w)}(\cap(f(w)) \cap\right.$

$$
\begin{aligned}
& \left.\left.\lambda w_{1} \cdot \exists d \exists x[\text { hate }(d)(x) \text { (speaker })\left(w_{1}\right) \wedge d \geq d_{s}\right]\right) \rightarrow \\
& \left.\left.w^{\prime} \in \lambda w_{2} . \text { ly }\left[\exists d[\text { hate }(d)(y) \text { (speaker })\left(w_{2}\right) \wedge d \geq d_{s}\right]\right]=\text { bad_acting }\right]
\end{aligned}
$$

According to (17b), (17a) is thus true in a world of evaluation $w$ iff every world that is

a) compatible with everything that is known in $w$, 
b) conforms as much as possible to stereotypical assumptions about the course of events in $w$, and where

c) there is an individual that the speaker hates to a degree that is at least as high as the value that has been assigned to the free variable $d_{s}$ on the basis of contextual information

is also a world where the unique individual that the speaker hates (at least) to the contextually specified degree in that world is identical to bad acting.

As already mentioned in section 1 , for the sentence to be true under this reading in a world $w$ there can be at most one entity that the speaker hates (at least) to the contextually specified degree. In addition to that, by uttering the conditional in (17a) instead of the sentence in (18), i.e. by invoking universal quantification over epistemically accessible (and stereotypical) worlds instead of making a direct claim about the world of evaluation, the speaker at least strongly implicates that she is not sure whether there actually is an entity in the world of evaluation that she hates to the contextually specified degree.

(18) I hate bad acting.

Now, since people can (at least in ordinary circumstances) be assumed to know about (the intensity of) their own feelings, this reading is strongly dispreferred for (17a), and the sentence accordingly is much more likely to receive a reading of the kind that will be dealt with in detail in section 4 . The same holds for (1c) (repeated here as (19a)), but (1b) and (8a) (repeated here as (19b) and (19c) may well be interpreted along the lines just sketched if the context does not suggest otherwise.

a. If any book impressed me, it was Ulysses.

b. If anyone was drunk at last night's party, it was Mary.

c. If anybody/somebody understands the work of Michael Haneke, it's Isabelle Huppert.

Concerning (19b), for example, it is easy to imagine a situation where the speaker (a) is not sure whether anyone drank enough at the party under discussion to qualify as being drunk according to the contextually specified standard, but (b) Mary is the only one among the guests she considers capable of such a behavior. Likewise, (19c) may well be uttered by someone who thinks (a) that the work of Michael Haneke is so obscure that possibly nobody understands it at all, but (b) that Isabel Huppert is the only one whose hermeneutic capabilities are so extraordinary that she might even succeed in this case.

In this section we have seen in detail what readings we get for the sentences introduced in sections 1 and 2 if we combine standard assumptions about the seman- 
The metalinguistic use of vague predicates in conditionals

tics of conditionals, vague predicates and clefts. In addition to that, I have shown that at least in some cases these readings are actually available options that might even be favored by the context. Consequently, there seems to be a real ambiguity between the readings discussed in this section and the ones sketched in sections 1 and 2. Intuitively, what is at stake is whether the standard of interpretation for the respective antecedent predicate is fixed by the context for all the worlds quantified over by the conditional, or whether it is possible to quantify over worlds that differ from the world of evaluation with respect to the standard of interpretation for the antecedent predicate. The analysis of vague predicates discussed in this section only allowed for the first option, thus resulting in readings according to which actual states of affairs, and not standards of interpretation are at issue. In the next section we will discuss a more flexible approach that is at least in principle compatible with the second option.

\section{The 'unexpected' readings}

\subsection{Barker's (2002) analysis of vague predicates}

The starting point for Barker (2002) is the observation that a sentence such as (20) can not only be used to convey information about Feynman's height, but also to "communicate something about how to use a certain word appropriately" (Barker 2002: 2) - for example in a situation where Feynman's height is common knowledge, but where the speaker has been asked what counts as tall in her country.

(20) Feynman is tall.

(Barker 2002: 2, ex. (1))

Barker calls such uses 'metalinguistic uses', and the task of his analysis is to account for both these uses and descriptive uses where the speaker conveys information about extralinguistic states of affairs within a single framework. In order to achieve this goal, Barker adopts a dynamic approach to meaning which models the shared beliefs of the discourse participants as a set of propositions whose intersection gives the set of worlds that are compatible with everything that both speaker and hearer(s) believe (Stalnaker 1973; Karttunen 1974; Heim 1982, 1983). This set of worlds, each of whose members represents an alternative way the world could be like given the shared beliefs of speaker and hearer(s), is called the context set (henceforth: $C$ ). The assertion of a proposition $\alpha$ then has the effect of mapping $C$ to the subset that is compatible with $\alpha$ by eliminating from $C$ all worlds in which $\alpha$ is not true, i.e. $C$ is in effect intersected with the set of worlds where $\alpha$ is true, resulting in $C^{\prime}$.

What is crucial for our purposes is that Barker enriches this system in the following way: He assumes a special delineation function $d$ which when it is applied 
to a world $c$ in the context set $C$ and to a vague predicate $\alpha$ returns the standard that is associated with $\alpha$ in $c$. Just like in the analysis sketched in section 3, this standard is conceived of as the minimal degree to which an individual has to satisfy a certain predicate in order to fall under the denotation of this predicate, i.e. the minimal degree to which an individual has to be tall in order to count as (absolute) tall, for example. An adjective such as tall is then interpreted as shown in (21a), and the example (20) receives the denotation in (21b):

$$
\begin{aligned}
& \text { a. } \llbracket \text { tall } \rrbracket=\lambda C .\{c \in C: c \in \operatorname{tall}(d(c)(\llbracket t a l l \rrbracket), x)\} \quad \text { (Barker 2002: 7, ex. } \\
& \text { (5)) } \\
& \text { b. } \lambda C .\{c \in C: c \in \operatorname{tall}(d(c)(\llbracket t a l l \rrbracket), f)\} \quad \text { (Barker 2002: 8, ex. (6b)), } \\
& \text { where } f \text { is the individual named Feynman. }
\end{aligned}
$$

Depending on the context, the assertion of (21b) either has the effect of excluding worlds from the initial context set on the basis of Feynman's height, or on the basis of the interpretation standard that is in effect for the predicate tall: Consider first the case where Feynman's actual height is not known among the discourse participants, while the interpretation standard for tall is fixed. In this case, the worlds in $C$ differ with respect to Feynman's height, but they agree on the degree denoted by $d(c)(\llbracket t a l l \rrbracket)$. Consequently, as soon as $(21 \mathrm{~b})$ has been asserted, all worlds where the maximal degree to which Feynman is tall is below that degree are excluded from $C$. This corresponds to the descriptive use.

Consider next the case where Feynman's height is common knowledge among the discourse participants, while the interpretation standard for tall is not fixed. In this case, the worlds in $C$ agree on the maximal degree to which Feynman is tall, while they differ with respect to the degree denoted by $d(c)(\llbracket t a l l \rrbracket)$. Consequently, as soon as (21b) has been asserted, all worlds where this degree is higher than the maximal degree to which Feynman is tall are excluded from $C$. This corresponds to the metalinguistic use.

What makes this analysis attractive for our purposes is the fact that it allows the standard of interpretation that is associated with a vague predicate to vary across worlds. Let us see what it can actually do for us with respect to the 'unexpected readings' under consideration.

\subsection{The analysis}

Recall that we need to account for the fact that sentences like those in (17a) and (19) (repeated here as (22a)-(22d)) have prominent readings that can be paraphrased as in (23):

a. If I hate anything, it's bad acting. 
The metalinguistic use of vague predicates in conditionals

b. If any book impressed me, it was Ulysses.

c. If anyone was drunk at last night's party, it was Mary.

d. If anybody/somebody understands the work of Michael Haneke, it's Isabelle Huppert.

a. What I hate most is bad acting.

b. The book that impressed me most was Ulysses.

c. The drunkest person at last night's party was Mary.

d. The one who understands the work of Michael Haneke best is Isabelle Huppert.

As already said above, what we would need in order to account for these readings is a way to manipulate the standards according to which the antecedent predicates are interpreted in such a way that we quantify over worlds that do not (possibly) differ from the world where the sentences are uttered with respect to some extralinguistic state of affairs, but only in the following way: The standards of interpretation have been raised so much as to prevent all entities from satisfying the predicates but the ones that satisfy them to the highest degree. I.e. in the case of (22a), for example, the degree $d$ to which a person $x$ needs to hate an entity $y$ at least in order for the triple $\langle x, y, d\rangle$ to fall under the denotation of hate must be set so high that there is only one entity of which it can be said that it is hated by $x$.

Now, as we have seen in section 4.1, Barker's system in principle allows us to perform the required manipulations, since it allows predicates to be associated with different standards in different worlds. There seems to be a rather straightforward way to get what we want: We could simply stipulate that in the cases at hand the covert modal quantifies only over those epistemically accessible worlds (that are best with respect to a stereotypical ordering source) where the standard associated with the antecedent predicate has been raised to the maximal value that is considered as a candidate in the respective context. A sentence such as (22a) would thus be interpreted as given in (24):

$$
\begin{aligned}
& \lambda C .\left\{c \in C: \forall c^{\prime}\left[c ^ { \prime } \in \operatorname { m a x } _ { g ( c ) } \left(\left\{c^{\prime \prime}: c^{\prime \prime} \in \cap(f(c)) \wedge d\left(c^{\prime \prime}\right)(\llbracket \text { hate } \rrbracket)=d_{\max } \wedge\right.\right.\right.\right. \\
& \left.\left.\exists x\left[\text { hate }\left(d\left(c^{\prime \prime}\right)(\llbracket \text { hate } \rrbracket), s p, x\right)\left(c^{\prime \prime}\right)\right]\right\}\right) \rightarrow \imath y\left[\text { hate }\left(d\left(c^{\prime}\right)(\llbracket \text { hate }), s p, y\right)\left(c^{\prime}\right)\right]= \\
& \text { bad_acting }]\}
\end{aligned}
$$

'All worlds $c^{\prime}$ that are (a) epistemically accessible from the worlds in the context set, that are (b) best with respect to a stereotypical ordering source, in which (c) $d\left(c^{\prime}\right)(\llbracket$ hate $\rrbracket)$ is set to the maximal value and in which there (still) is some entity such that the speaker hates this entity (at least) to the

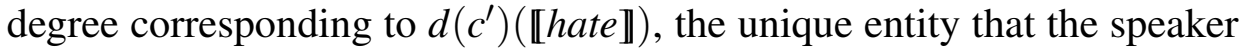
hates (at least) to the degree corresponding to $d\left(c^{\prime}\right)(\llbracket$ hate $\rrbracket)$ is identical to bad acting.' 
At first sight, this solution looks not too bad. It raises at least two serious problems, though. First, it is not at all clear why we should be allowed to enrich the predicate restricting the covert modal in this way, i.e. why (and at which level) the conjunct $d(c)(\llbracket h a t e \rrbracket)=d_{\max }$ is inserted. Second, it is not clear how we can ensure that $d_{\max }$ is exactly the degree that we need, i.e. the one that filters out all but the one entity that the speaker hates to the highest degree. Why shouldn't it be the case that the highest degree that is considered as a plausible candidate for $d(c)$ (匹hate $\rrbracket)$ in the relevant context is one according to which there are two, three, or even more entities that the speaker hates to a degree that is at least as high? Dropping the assumption that $d_{\text {max }}$ can only be set to a degree that is considered as a plausible candidate in the respective context would make matters even worse, for then there would be no worlds for the covert modal to quantify over, and the sentence would be vacuously true: Sadly enough, there does not seem to be an upper bound for the intensity with which someone or something can be hated, so $d_{\max }$ would be undefined, and there simply wouldn't be any worlds that satisfy the restriction of the modal operator.

There is a further aspect of the strategy just sketched that is problematic, but which is also brought up by the solution I will propose below, and therefore needs to be dealt with anyway: As already said in sections 1 and 2, the sentences under consideration can be uttered in situations where it is common knowledge among the discourse participants that there are other entities that satisfy the respective predicate (after all, this was one of the observations that motivated the analysis to be proposed in this section). The sentence in (22a), for example, can be uttered even if it is common knowledge among the discourse participants that the speaker hates other things. In present terms, this means that (the denotation of) the sentence can be applied to a context set from which all worlds $c$ have been eliminated in which the

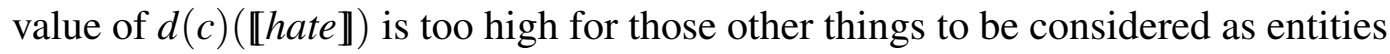
that are hated by the speaker.

But what consequences does this have for the worlds quantified over by the covert modal? Since the modal base $f$ is epistemic by assumption, it returns for each world $c$ in the context set the set of propositions that are known in $c$. Now, the crucial question is whether this set of propositions also contains knowledge about the standards of interpretation for vague predicates in $c$. If this was the case, $\cap(f(c))$

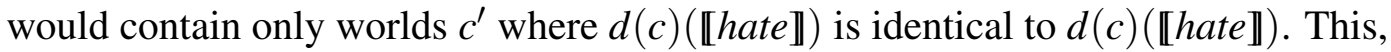
however, would mean that there were now worlds $c^{\prime}$ in $\cap(f(c))$ where it is true that $d\left(c^{\prime}\right)(\llbracket$ hate $\rrbracket)$ is identical to $d_{\max }$, simply because the context set $C$ does not contain any worlds $c$ where $d(c)(\llbracket h a t e \rrbracket)$ is identical to $d_{\max }$. Consequently, there wouldn't be any worlds for the covert modal to quantify over, and the sentence would come out as vacuously true again.

While the problem just outlined could simply be seen as a further argument against the analysis under consideration, the problem is more general, since it affects 
The metalinguistic use of vague predicates in conditionals

any analysis that allows the standard of interpretation associated with the antecedent predicate to be higher in the worlds quantified over by the covert modal than in the worlds of the context set. But this is exactly what we need! Let us therefore assume that it is at least possible for the modal base introduced by the covert epistemic operator in conditionals to exclude knowledge concerning the standards of interpretation associated with vague predicates in a world $c$ from the set of propositions to which it maps $c$. Consequently, $\cap(f(c))$ is allowed to contain worlds where the standards of interpretation associated with vague predicates are higher or lower than in $c$. Since it is well-known that a proper understanding of utterances containing modals in general requires some flexibility with respect to the question of which aspects of the contexts in which they are uttered may be ignored, and since metalinguistic knowledge concerning the standards of interpretation associated with vague predicates is a quite special and clearly delineated kind of knowledge, this seems to be a legitimate option.

A further fact that seems relevant for the question of whether knowledge concerning the standards of interpretation associated with vague predicates may be excluded from the modal base is the behavior of subjunctive conditionals with respect to the availability of the readings under consideration. Consider the subjunctive counterparts of the conditionals from (22) above:

a. If I hated anything, it would be bad acting.

b. If any book had impressed me, it would have been Ulysses.

c. If anyone had been drunk at last night's party, it would have been Mary.

d. If anybody/somebody understood the work of Michael Haneke, it would be Isabelle Huppert.

Interestingly, none of the sentences in (25) receives an 'unexpected reading', i.e. a reading that can be paraphrased as in (23). Rather, they all strongly suggest that the state of affairs corresponding to the antecedent does not hold in the world of evaluation, i.e. that there is nothing the speaker hates, no book that impressed her, etc. Now, according to a (in my view) very plausible assumption about the semantic impact of subjunctive vs. indicative marking in conditionals that goes back to Stalnaker (1968), the worlds where the antecedent is true are required to (a) lie outside of the context set, and (b) be as similar as possible to the world of evaluation as is allowed by the truth of the antecedent predicate in them. In terms of the theory of conditionals adopted in this paper, this means that the modal base is empty in the case of subjunctive conditionals (i.e. all possible worlds where the antecedent predicate is true are allowed), while the ordering source orders the worlds it operates on according to their overall similarity to the world of evaluation. 
Now, if excluding knowledge concerning the standards of interpretation associated with vague predicates was not allowed for the modal base employed in indicative conditionals, choosing the subjunctive counterpart of the respective conditional would be the natural option for expressing the intended meaning. After all, the intended reading involves quantification over worlds that differ from the worlds in the context set only insofar as the standard of interpretation associated with a certain vague predicate has been raised. I therefore take the fact that the sentences in (25) in contrast to their indicative counterparts do not receive metalinguistic readings to be an indication that it is allowed to exclude knowledge concerning the standard of interpretation associated with vague predicates from the set of propositions the modal base in indicatives assigns to a world. Hence, there is no competition between indicatives and subjunctives with respect to that matter, and choosing a subjunctive instead of an indicative is automatically taken to indicate that the worlds where the antecedent is true differ from the worlds in the context set with respect to an actual state of affairs, and not simply with respect to the standard according to which the vague predicate is interpreted.

Following the analysis sketched above, the sentences in (25) are thus interpreted as follows: Since the modal base is empty by assumption, we get the set of all possible worlds where the speaker hates an entity according to some conceivable standard of interpretation. Since the selection function picks only those worlds from that set that are maximally similar to the world of evaluation, all surviving worlds are such that the standard of interpretation associated with the respective predicate is the same as in the word of evaluation. Consequently, the sentence in (25a), for example, at least strongly implicates that it is incompatible with the context that there is an entity that the speaker hates at least to the contextually relevant degree, and likewise for the other examples.

Let us now return to the question of how we can account for the metalinguistic readings of the indicative conditionals in (22). Intuitively, we want the covert modal to quantify over worlds that only differ from the world of evaluation in the following way: The standard of interpretation associated with the respective predicate has been set to a value that is so high that it filters out all entities but the one that satisfies the predicate to the highest degree in the world of evaluation, but not higher. But how can this be ensured? The idea I would like to pursue is that we employ the selection function to achieve this goal: Instead of picking out worlds that are best with respect to a stereotypical (or some other) ordering source, i.e. satisfy as many propositions as possible from the ordering source, it picks out worlds that are best in terms of the strictness that is applied to the interpretation of vague predicates. Concerning the case of the verb hate, for example, the selection function would pick out those worlds $c^{\prime}$ where $d(c)(\llbracket$ hate $\rrbracket)$ is highest. 
The metalinguistic use of vague predicates in conditionals

Recall that we allow the epistemic modal base to ignore the standards of interpretation that are associated with vague predicates in the respective context. Accordingly, the selection function operates on all words $c^{\prime}$ that are (a) compatible with what is known in the respective world $c$ from the context set apart from the standard of interpretation associated with vague predicates, and where (b) the antecedent of the conditional is true. Note that the required compatibility with everything else that is known in $c$ in combination with the existential quantifier in the antecedent automatically sets an upper limit for the standard associated with the respective antecedent predicate. To see this, consider the case of (22a): Since only worlds $c^{\prime}$ are allowed where the actual relations holding between entities and degrees are compatible with what is known in $c$, and since the antecedent requires there to be at least one entity that the speaker hates (at least) to the degree corresponding to

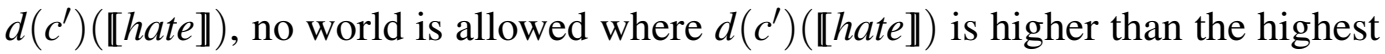
degree for which (it is known that) there is an entity $x$ in $c$ such that the speaker hates $x$ to the degree corresponding to $d\left(c^{\prime}\right)$ (匹hate $\left.\rrbracket\right)$ in $c$. The selection function

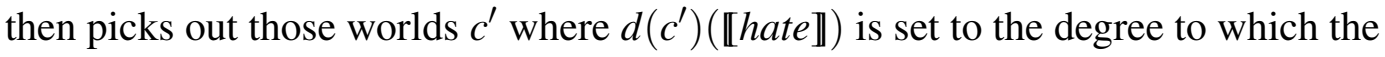
speaker hates the entity that she hates most in the respective world $c$ in the context set. This gives us exactly what we want, and avoids the problems with finding the right value for $d_{\text {max }}$ discussed above.

The definition for a strict partial order over standards of interpretation for vague predicates that orders worlds according to how strict they apply those standards is given in (26a), and the corresponding selection function is defined in (26b).

$$
\begin{aligned}
& \text { a. } \forall c^{\prime}, c^{\prime \prime}: c^{\prime}<_{d P} c^{\prime \prime} \text { iff } d\left(c^{\prime}\right)(P)>d\left(c^{\prime \prime}\right)(P) \\
& \text { b. } \forall C \subseteq C: \max _{d P}\left(C^{\prime}\right)=\left\{c \in C^{\prime}: \neg \exists c^{\prime} \in C^{\prime}: c^{\prime}<_{d P} c\right\}
\end{aligned}
$$

Taking everything together, we get (27b) as the formal representation of the metalinguistic interpretation of the sentence in (22a), which is repeated here as (27a):

a. If I hate anything, it's bad acting.

b. $\quad \lambda C .\left\{c \in C: \forall c^{\prime}\left[c^{\prime} \in \max _{d \llbracket \text { hate } \rrbracket}\left(\left\{c^{\prime \prime}: c^{\prime \prime} \in \cap\left(f^{-}(c)\right) \wedge\right.\right.\right.\right.$

$\exists x\left[\right.$ hate $\left(d\left(c^{\prime \prime}\right)(\llbracket\right.$ hate $\left.\left.\left.\left.\rrbracket), s p, x\right)\left(c^{\prime \prime}\right)\right]\right\}\right) \rightarrow$

$\imath y\left[\right.$ hate $\left(d\left(c^{\prime}\right)(\llbracket\right.$ hate $\left.\left.\rrbracket), s p, y\right)\left(c^{\prime}\right)\right]=$ bad_acting $\left.]\right\}$,

where $f^{-}$is the modal base that results from excluding knowledge concerning the standards of interpretation of vague predicates from the epistemic modal base $f$.

'In all worlds $c^{\prime}$ that are (a) epistemically accessible from the worlds in the context set, apart from the fact that the standards of interpretation that are associated with vague predicates may differ from the ones in those worlds, where (b) the verb hate is interpreted according to the strictest standard that is possible, and where 
(c) there is some entity such that the speaker hates this entity at least to the degree corresponding to $d\left(c^{\prime}\right)$ (【hate $\left.\rrbracket\right)$, the unique entity that the speaker hates at least to the degree corresponding to $d\left(c^{\prime}\right)(\llbracket$ hate $\rrbracket)$ is identical to bad acting.'

\section{Conclusion}

In this paper I have shown that indicative conditionals whose antecedents contain vague predicates (and predicates whose denotations can be shifted in such a way that they become vague) under certain conditions are capable of receiving metalinguistic readings, i.e. readings according to which the worlds quantified over do not (possibly) differ from the world of evaluation with respect to some (extralinguistic) state of affairs, but only with respect to the standards according to which those vague predicates are interpreted - they can be set to values that are higher than the ones that are in effect in the worlds of evaluation. Under these readings, the sentences are equivalent to ones stating which individuals satisfy the respective predicate to the highest degree in the world of evaluation.

I have argued that the metalinguistic readings come about as the result of an interplay of the following factors: First, it is possible to exclude the standards of interpretation for vague predicates from the epistemic modal base that is assigned to the world of evaluation. Secondly, the selection function operating on the intersection of the sets of worlds in the modal base may not only pick out worlds that are best with respect to a stereotypical (or some other) ordering source, but may also pick out worlds that are best with respect to how strict the standards are that they apply to the interpretation of vague predicates.

This proposal raises a number of issues which need further exploration, but which are beyond the scope of this paper, and therefore have to be left as questions for future research: First, are there other kinds of information that can be excluded from epistemic modal bases? Second, what is the exact nature of the discourse conditions that license the metalinguistic readings under discussion? Third, what are the conditions determining whether a non-gradable predicate can be re-interpreted as a gradable one?

\section{References}

Barker, Chris. 2002. The dynamics of vagueness. Linguistics and Philosophy 25(1). 1-36. doi:10.1023/A:1014346114955.

von Fintel, Kai. 1997. Bare plurals, bare conditionals, and Only. Journal of Semantics 14(1). 1-56. doi:10.1093/jos/14.1.1.

von Fintel, Kai. 1999. NPI licensing, Strawson entailment, and context dependency. Journal of Semantics 16(2). 97-148. doi:10.1093/jos/16.2.97. 
The metalinguistic use of vague predicates in conditionals

von Fintel, Kai \& Sabine Iatridou. 2005. What to do if you want to go to Harlem: Notes on anankastic conditionals and related matters. Ms., MIT.

Gillies, Anthony S. 2010. Iffiness. Semantics and Pragmatics 3. 1-42. doi:10.3765/sp.3.4.

Hedberg, Nancy. 2000. The referential status of clefts. Language 76(4). 891-920. doi: $10.2307 / 417203$.

Heim, Irene. 1982. The semantics of definite and indefinite noun phrases. Amherst, MA: University of Massachusetts dissertation.

Heim, Irene. 1983. On the projection problem for presuppositions. In D. Flickinger (ed.), Proceedings of the Second West Coast Conference on Formal Linguistics, 114-125. Stanford, CA: Stanford University Press.

Karttunen, Lauri. 1974. Presuppositions and linguistic context. Theoretical Linguistics 1(1-3). 181-194. doi:10.1515/thli.1974.1.1-3.181.

Kennedy, Chris. 1999. Projecting the adjective: The syntax and semantics of gradability and comparison. New York: Garland Press.

Kennedy, Chris. 2007. Vagueness and grammar: The semantics of relative and absolute gradable adjectives. Linguistics and Philosophy 30(1). 1-45. doi:10.1007/s10988-006-9008-0.

Kratzer, Angelika. 1981. The notional category of modality. In H.-J. Eickmeyer \& H. Rieser (eds.), Words, worlds and contexts: New approaches in word semantics, 38-74. Berlin: Walter de Gruyter.

Kratzer, Angelika. 1986. Conditionals. Chicago Linguistics Society 22. 1-15.

Nolan, Daniel. 2003. Defending a possible-worlds account of indicative conditionals. Philosophical Studies 116(3). 215-269. doi:10.1023/B:PHIL.0000007243.60727.d4.

Stalnaker, Robert. 1968. A theory of conditionals. In N. Rescher (ed.), Studies in logical theory, vol. 2 American Philosophical Quarterly Monograph Series, 98-122. Oxford: Basil Blackwell.

Stalnaker, Robert. 1973. Presuppositions. Journal of Philosophical Logic 2(4). 447-457. doi:10.1007/BF00262951.

Stalnaker, Robert. 1975. Indicative conditionals. Philosophia 5(3). 269-286. doi:10.1007/BF02379021.

von Stechow, Arnim. 1984. Comparing semantic theories of comparison. Journal of Semantics 3(1-2). 1-77. doi:10.1093/jos/3.1-2.1. 
Stefan Hinterwimmer

Dr. Stefan Hinterwimmer

IKW

Universität Osnabrück

Albrechtstraße 28, 49076 Osnabrück

Germany

shinterw@uni-osnabrueck.de 